www.periodicos.unimontes.br/index.php/caminhosdahistoria

\title{
ÀS MARGENS DOS SERTÕES: A ECONOMIA DE ABASTECIMENTO E PEQUENO ESCRAVISTA DO VALE DO MACACU - SÉCULO XVIII
}

\author{
Vinicius Maia Cardoso ${ }^{1}$
}

Resumo: As relações de perfil econômico no Vale do Macacu, no século XVIII, se voltaram para uma agricultura de abastecimento com base numa estrutura pequeno-escravista, não tendo a atividade de agricultura para exportação um caráter dominante, nem propriedades com muitos escravos como seu modelo de utilização de mão-de-obra. Essa estrutura de produção atendeu inclusive as necessidades de abastecimento para as ações de ocupação, controle e repovoamento dos Sertões do Macacu, no século XVIII. O artigo busca apresentar um quadro parcial da produção de gêneros alimentícios no entorno dos Sertões do Macacu, possível graças à presença de uma economia voltada para abastecimento não apenas das freguesias em si, mas disponíveis para sustento dos agentes sociais envolvidos na ocupação dos referidos Sertões.

Palavras-chave: Abastecimento; Sertões do Macacu; Século XVIII; Economia; farinha de mandioca.

Abstract: The economic profile relations in the Macacu Valley, in the 18th century, turned to a supply agriculture based on a small-slave structure, with no dominant agricultural activity for export, nor properties with many slaves as their model of labor use. This production structure even met the supply needs for the occupation, control and repopulation actions of the Sertões do Macacu, in the 18th century. The article seeks to present a partial picture of the production of foodstuffs in the surroundings of the Sertões do Macacu, made possible thanks to the presence of an economy aimed at supplying not only the parishes themselves, but also available for the sustenance of the social agents involved in the occupation of the hinterland.

Keywords: Supply; Macacu Hinterland; 18th Century; Economy; Cassava flour.

Os Sertões do Macacu se constituíram, na segunda metade do século XVIII, como região aurífera de exploração tardia na capitania do Rio de Janeiro, território limitado a Sul pelo rio Macacu, a Norte pelo rio Paraíba do Sul, fronteira com Minas Gerais; a Oeste pela freguesia de Inhomirim (Magé); a Leste Campos dos Goytacazes e Macaé. O presente artigo se relaciona aos esforços da pesquisa de doutoramento intitulada "Pouco conhecido, montuoso e emboscado: Poder e Economia nos Sertões do Macacu - 1750 a 1800”, a qual busca analisar redes de relacionamentos voltadas para a economia e relações de poder nesses sertões. O recorte temporal se circunscreve ao período pombalino e pós-pombalino, entre os

\footnotetext{
${ }^{1}$ Doutorando em História, Professor no Departamento de Educação à Distância (EAD) da Universidade Salgado de Oliveira (Niterói/RJ), Gestor do Curso de História do Departamento de Educação à Distância (EAD) da Universidade Salgado de Oliveira (Niterói/RJ). E-mail: maia-vinicius@hotmail.com. ORCID: https://orcid.org/0000-0001-7175-4449
} 
governos dos vice-reis conde de Atouguia, de 1749 a 1754 e José Luís de Castro (conde de Resende), entre 1790 e 1801, em função das fontes acerca dos Sertões e suas áreas limítrofes.

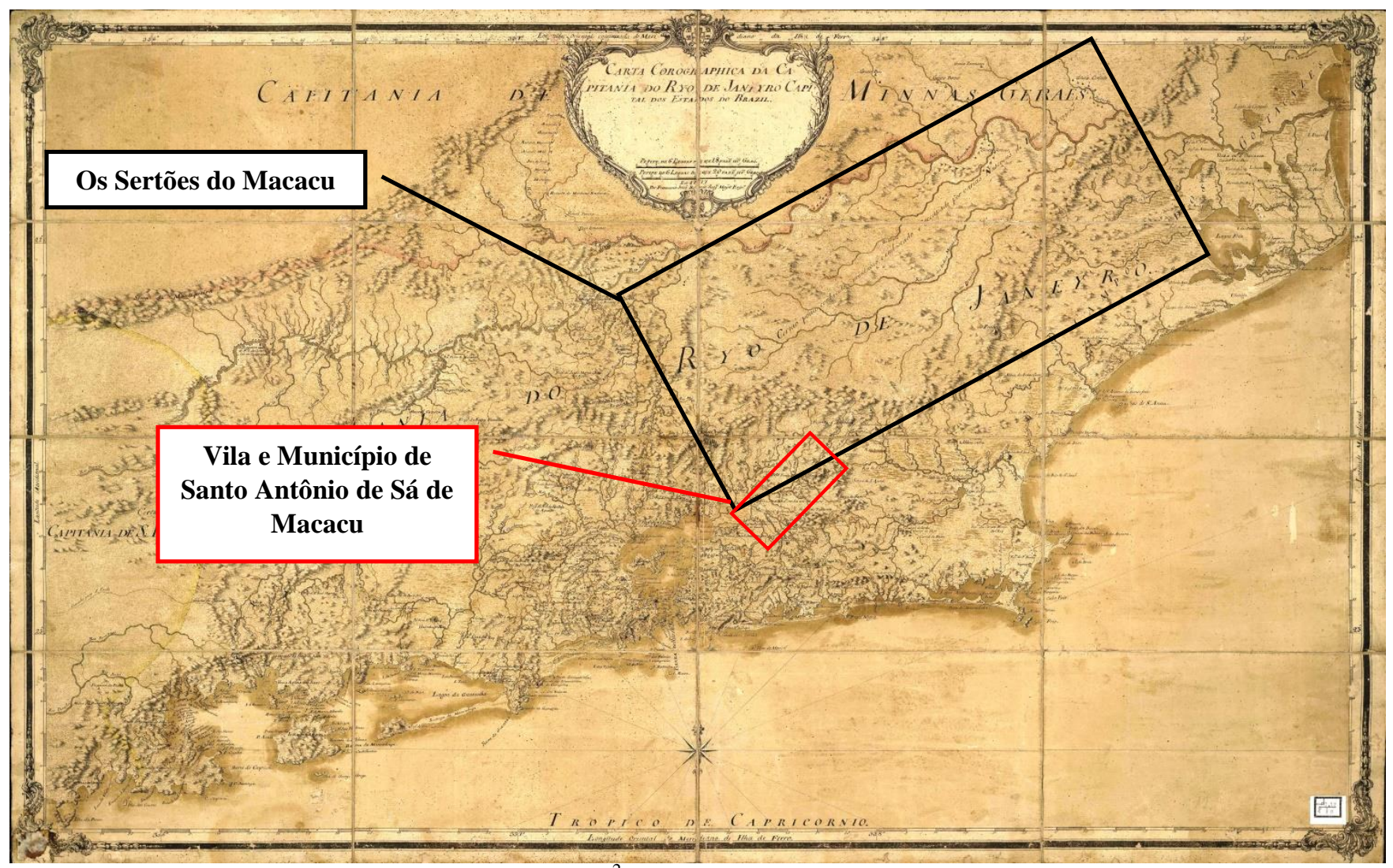

MAPA 1 - Os Sertões do Macacu - 1777. Fonte: ${ }^{2}$

A sua ocupação demandou uma série de providências do Estado para o abastecimento das tropas militares coloniais envolvidas, bem como dos ocupantes de terras minerais ou agricultáveis, de escravos negros e de indígenas envolvidos com transporte de gêneros, abertura de estradas, condução de canos nas travessias dos muitos rios que cortam a região.

Também os muares empregados para transporte de gêneros necessitaram de atendimento em suas necessidades alimentares, com o uso do milho como complemento da alimentação através de pastos disponíveis. Nesse sentido, as freguesias subordinadas à vila de Santo Antônio de Sá (1697), também denominada vila de Macacu, constituirão locais de produção de alimentos, uma característica marcante na economia dessa região (CARDOSO, 2012).

O artigo busca apresentar um quadro parcial da produção de gêneros alimentícios no entorno dos Sertões do Macacu, possível graças à presença de uma economia voltada para

${ }^{2}$ ROSCIO, Francisco João. Carta corographica da capitania do Ryo de Janeyro, capital dos estados do Brasil. [S.1.: s.n.], 1777. 1 mapa ms., desenho a nanquim, 58 x 94,5cm em f. 60 x 96,5. Disponível em: <http://objdigital.bn.br/acervo_digital/div_cartografia/cart534317.htm>. Acesso em: 16 jul. 2019. 
abastecimento não apenas das freguesias em si, mas disponíveis para sustento dos agentes sociais envolvidos na ocupação dos referidos Sertões. Havia uma dinâmica produção econômica de alimentos para mercado interno na capitania do Rio de Janeiro, sendo essa produção expressiva na região do vale do Macacu. Em toda a região do entorno da baía da Guanabara, conforme demonstra o Mapa 1, enfocando o que Francisco Carlos Teixeira da Silva denomina como "cinturão mandioqueiro."

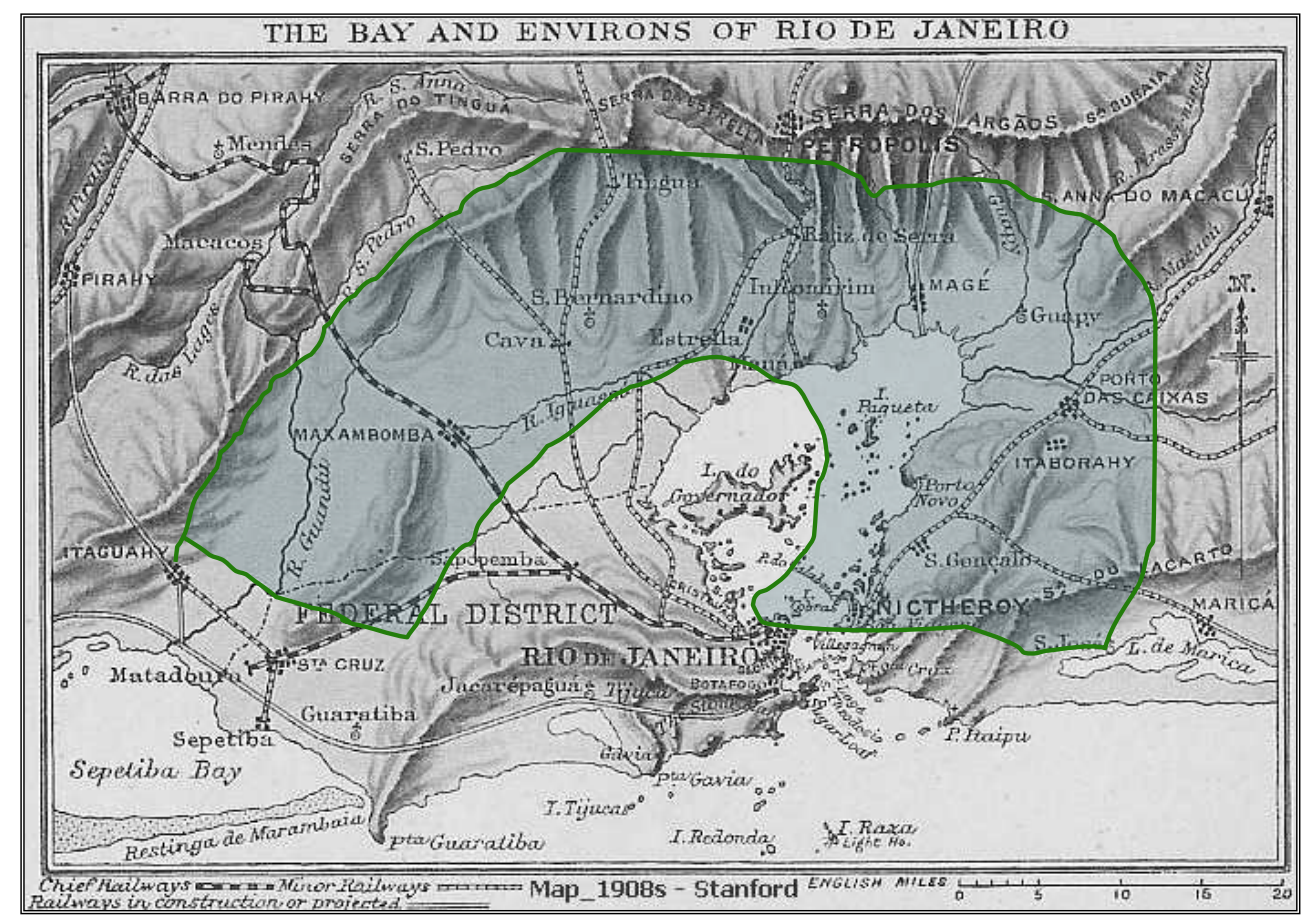

MAPA 1- Cinturão mandioqueiro no século XVIII. Fonte: The Bay and Environs of Rio de Janeiro, 1908.

Segundo ainda Francisco Carlos Teixeira da Silva:

As maiores freguesias produtoras de alimentos, de toda a capitania eram as de Cabo Frio, Campos, Santíssima Trindade, Itaboraí e Jacutinga, com amplo predomínio do cultivo da mandioca e o fabrico de farinha. Porém, por todas as informações que possuímos, a produção de Cabo Frio e de Campos estava voltada para o seu próprio abastecimento, em particular do seu vasto hinterland açucareiro, e não desempenhava nenhum papel de monta no abastecimento do Rio de Janeiro. (SILVA, 1990, 166-167)

Também informa que a produção de alimentos para o Rio de Janeiro concentrava-se no recôncavo da Baía da Guanabara e Sertão da capitania, com 22 freguesias na atividade: "75\% de toda a produção de farinha da capitania; $86 \%$ de todo o arroz, $81 \%$ do milho e $60 \%$ da produção de feijão" (SILVA, 1990, p. 166-167). Era também o arroz objeto da política econômica portuguesa devido 
a toda uma política de fomento baseada em dois eixos centrais: de um lado, as isenções fiscais patrocinadas pela Coroa, por 10 anos, desde 1760, e renovadas em seguida; por outro lado, a garantia de compra, com preços préestabelecidos, com o patrocínio do governador associado a mercadores de Lisboa. (SILVA, 1990, 166-167)

Uma produção de mais de 20 mil alqueires $(604.500 \mathrm{~kg})$ de arroz graúdo e 30 mil $(906.750 \mathrm{~kg})$ de arroz pequeno, plantado por cerca de 300 lavradores na capitania:

a cultura do arroz consolidou-se na capitania constituindo um amplo arco do fundo da Baía da Guanabara até Itaboraí, com Iguaçu produzindo $24 \%$ do arroz colhido, Pilar do Iguaçu (Duque de Caxias), 8\%; Santo Antônio de Sá e Itaboraí, com 7\% cada; Suruí, com 6\% e Pacobaíba, com 5\%. (SILVA, 1990, 169)

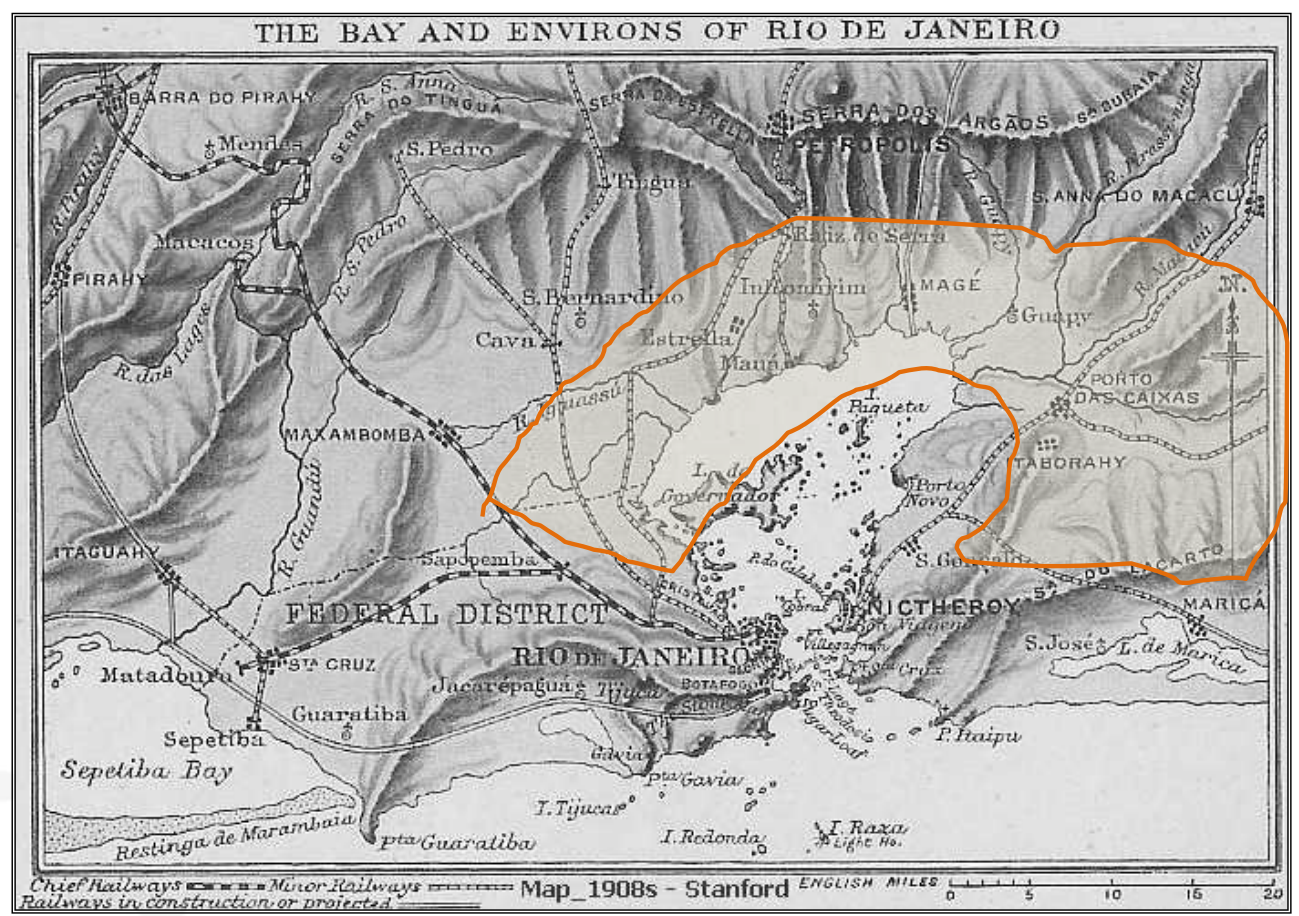

MAPA 2 - Cinturão do arroz no século XVIII. Fonte: The Bay and Environs of Rio de Janeiro, 1908.

Os mapas acima, de 1908 e que servem apenas de referencial, demonstram de forma aproximada a extensão dos arcos de produção de arroz e farinha no século XVIII. Observe-se a presença de vários rios, vias vitais de contato com o interior nos espaços integrantes do conjunto do império atlântico luso e que serviam para escoamento da produção até, no caso, a baía da Guanabara:

Assim, nos rios São João de Meriti, Sarapuí e Iguaçu, de um lado da baía, e o Macacu, Guapi e Guaraí, do outro lado, apresentavam um intenso movimento comercial. Só Cachoeiras de Macacu tinha 24 portos visitados por saveiros e barcos, enquanto em Pilar do Iguaçu mais de 100 barcos transportavam exclusivamente mantimentos. (SILVA, 1990, 172) 
Tomando-se o Relatório do Lavradio, este apresenta, para Macacu, no ano de 1778, a presença de 35 barcos para "condução de mantimentos e mais feitos"3, além de uma barca com a mesma função. Para o transporte da produção até os portos de embarque, o relatório lista também 53 "Carros de conduzir mantimentos além de outros de pescaria". 4 Outro produto, a farinha de mandioca, constituía-se no maior gênero agrícola em relação à quantidade, produzido na capitania do Rio de Janeiro.

O cultivo da mandioca, e o fabrico da farinha, era praticamente universal na capitania, com uma grande concentração nas freguesias da Jacutinga, com $11,6 \%$ do total da produção; Santíssimo Sacramento*, com 11,3\%; delineando assim um grande cinturão mandioqueiro que se extendia pelos atuais municípios de Duque de Caxias, Nova Iguaçu, Cachoeiras de Macacu e Itaboraí. (SILVA, 1990,172)

Ainda segundo o Relatório do marquês do Lavradio, a vila de Macacu (Santo Antonio de Sá) e suas freguesias, possuíam perto de 17.329 habitantes, sendo 8.371 livres e 8.958 escravos e 2.085 residências, com área total aproximada de $1.500 \mathrm{~km}^{2}$.

\begin{tabular}{|c|c|c|c|c|c|c|}
\hline Freguesia & Açúcar & Cachaça & Farinha & Feijão & Milho & Arroz \\
\hline \multirow{2}{*}{ Santo Ant ${ }^{\circ}$ de Sá } & \multirow{2}{*}{73 caixas } & \multirow{2}{*}{52 pipas } & 360.000 & 14.400 & 18.000 & 108.000 \\
\hline & & & litros & litros & litros & litros \\
\hline \multirow{2}{*}{ Ssma Trindade } & \multirow{2}{*}{26 caixas } & \multirow{2}{*}{15 pipas } & 1 milhão & 79.200 & 61.200 & 126.000 \\
\hline & & & litros & litros & litros & litros \\
\hline \multirow{2}{*}{ Guapimirim } & \multirow{2}{*}{50 caixas } & \multirow{2}{*}{5 pipas } & 324.000 & 72.000 & 7.200 & 90.000 \\
\hline & & & litros & litros & litros & litros \\
\hline \multirow{2}{*}{ Itambi } & \multirow{2}{*}{115 caixas } & \multirow{2}{*}{180 pipas } & 54.000 & 36.000 & 2.880 & 21.000 \\
\hline & & & litros & litros & litros & litros \\
\hline \multirow{2}{*}{ S.J. de Itaboraí } & \multirow{2}{*}{290 caixas } & \multirow{2}{*}{160 pipas } & 838.620 & 289.440 & 405.900 & 103.284 \\
\hline & & & litros & litros & litros & litros \\
\hline \multicolumn{3}{|c|}{ Uma arroba $=15 \mathrm{~kg}$} & \multicolumn{4}{|c|}{ Uma caixa $=35$ arrobas } \\
\hline
\end{tabular}

TABELA 1 - Produção agrícola da Vila e Município de Santo Antônio de Sá - 1778. Fonte: Relações Parciais do Marques do Lavradio - 1778.

Por serem medidas com mesma unidade (litros) ${ }^{5}$, foi possível calcular em percentuais a produção dos gêneros para abastecimento como farinha, feijão, milho e arroz do conjunto

\footnotetext{
${ }^{3}$ Relações Parciaes Apresentadas ao Marquez de Lavradio. 8 de outubro de 1778., 1980, p. 295.

${ }^{4}$ Relações Parciaes Apresentadas ao Marquez de Lavradio. 8 de outubro de 1778., 1980 ,p. 295.

${ }^{5}$ A unidade de litros como medida de sólidos pôde ser transformada em quilogramas por meio de uma fórmula de conversão, dando melhor percepção das quantidades.
} 
das freguesias do município de Santo Antonio de Sá. ${ }^{6}$ De um total de 4.011.124 litros, ou $1.819 .103 \mathrm{~kg}(100 \%)$ de gêneros produzidos (menos o açúcar e a aguardente), a farinha de mandioca correspondeu a 64,2\% da produção (2.576.620 litros ou $1.168 .535 \mathrm{~kg}$ ); o milho, $12,3 \%$ (495.180 ou $224.571 \mathrm{~kg}$ ); o feijão, $12,2 \%$ (491.040 ou $222.693 \mathrm{~kg}$ ) e o arroz $11,1 \%$ (448.284 litros ou $203.303 \mathrm{~kg}$ ).

Se considerado esse milhão de litros de farinha produzidos na freguesia da Santíssima Trindade, região que se insere na área objeto da pesquisa, alcança-se $453.514 \mathrm{~kg}$ de farinha, o que corresponde a $24,93 \%$ de toda a produção das freguesias da Vila. Se considerada unicamente a farinha, alcança-se o percentual de 38,8\% da totalidade do produto produzido apenas na freguesia da Santíssima Trindade. Por outro lado, nas Relações Parciaes Apresentadas ao Marquez de Lavradio, de 08 de outubro de 1778, todo o distrito de Macacu produziu 28 mil e 500 alqueires de farinha $(1.163 .662 \mathrm{~kg}), 2.900$ de feijão $(87.652 \mathrm{~kg}), 2.480$ de milho $(74.958 \mathrm{~kg})$ e $9.600 \mathrm{de} \operatorname{arroz}(290.160 \mathrm{~kg})$. Um total de 43.480 alqueires de produtos, sendo que novamente a farinha teve a primazia, com 65,5\% da produção. A produção de açúcar, em 17 engenhos, alcançou em 1778 um total aproximado de 273 caixas, perfazendo 9.555 arrobas ou 143.325 quilogramas. Somando-se a produção de açúcar com a de farinha, arroz, milho e feijão, alcançam-se 1.457.508 quilogramas, correspondendo o açúcar a apenas $9,83 \%$ desse total. $^{7}$

Já no manuscrito Correspondência e documentos relativos às novas Minas de Macacu ${ }^{8}$ produzido no final do século XVIII (1786-1790), acerca de notícias veiculadas da existência de ouro nos sertões de Cantagalo na capitania do Rio de Janeiro, ou seja, trata-se de fonte voltada especificamente para os Sertões do Macacu, encontram-se várias listagens de lavradores a quem o Estado comprou farinha para abastecimento das tropas de milícias. Tropas essas encarregadas de controlar o acesso e o contrabando do metal amarelo nas rotas de acesso às ambicionadas e supostas minas. Tal produção era armazenada no 'paiol da Caxoeira', localidade estabelecida provavelmente junto à subida da serra dos Órgãos. Segundo a fonte, o sargento-mor Joaquim José da Fonseca comunicava ao vice-rei do Brasil,

\footnotetext{
${ }^{6}$ O Relatório do Marquês do Lavradio não apresentou dados para a freguesia de N. Senhora da Conceição do Rio Bonito e de São João do Itaboraí, também integrantes do município e vila de Santo Antonio de Sá. (Para confirmar a formação distrital desta Vila, ver dados acerca desta freguesia em 'Visitas Pastoraes' de monsenhor Pizarro e Araújo, 1794-95. Cópia datilografada do original manuscrito. Arquivo da Cúria Metropolitana do Rio de Janeiro).

${ }^{7}$ Relações Parciaes Apresentadas ao Marquez de Lavradio. 8 de outubro de 1778.Op. Cit, p.289-295. As 9.55 arrobas equivalem a $143.325 \mathrm{~kg}$, que dividos pelo índice 30,225, equivalem a 4.741 alqueires (aproximado).

${ }^{8}$ Correspondência e documentos relativos as novas Minas de Macacu, do Rio de Janeiro, de que era superintendente Manuel Pinto da Cunha e Souza - 1786 a 1790. Seção de Manuscritos. Biblioteca Nacional. Catálogo 09,3,017-021.
} 
Luís de Vasconcelos e Sousa, conde de Figueiró (1778-1790), através de três cartas, de 14 de janeiro, 13 de fevereiro e 22 de maio de 1786, a aquisição de 899 alqueires $(27.172 \mathrm{~kg})$ de farinha de mandioca. Produto adquirido por compra a 196 lavradores das freguesias da Vila de Santo Antônio de Sá pelo preço global de quatrocentos e vinte e três mil cento e vinte réis (423\$120). Os dados nas cartas do sargento-mor permitiram construir a tabela abaixo:

\begin{tabular}{|c|c|c|c|c|c|c|c|}
\hline & $\begin{array}{c}\text { Alqueires } \\
\text { de farinha }\end{array}$ & $\begin{array}{c}\text { Número de } \\
\text { produtores }\end{array}$ & $\begin{array}{c}\text { Menor } \\
\text { preço } \\
\text { (réis } \\
\text { p/alqueire) }\end{array}$ & $\begin{array}{c}\text { Maior } \\
\text { preço } \\
\text { (réis } \\
\text { p/alqueire) }\end{array}$ & $\begin{array}{c}\text { Menor } \\
\text { entrega } \\
\text { (alqueires) }\end{array}$ & $\begin{array}{c}\text { Maior } \\
\text { entrega } \\
\text { (alqueires) }\end{array}$ & $\begin{array}{c}\text { Valor } \\
\text { total }\end{array}$ \\
\hline 14.01 .1786 & 210 & 29 & $\$ 360$ & $\$ 500$ & 01 & 24 & $87 \$ 960$ \\
\hline 13.02 .1786 & 467 & 121 & $\$ 320$ & $\$ 520$ & 01 & 32 & $218 \$ 720$ \\
\hline 22.05 .1786 & 222 & 46 & $\$ 400$ & $\$ 640$ & 01 & 20 & $116 \$ 440$ \\
\hline
\end{tabular}

TABELA 2 - Produção de farinha de mandioca na Vila de Santo Antonio de Sá. ${ }^{9}$

Entre os 196 produtores listados ${ }^{10}$, foi observada a presença de 22 mulheres $(11,2 \%)$ proprietárias de terras e plantações. Sheila de Castro Faria, em sua tese sobre a família no cotidiano colonial para Campos dos Goitacazes, afirma ser comum mulheres chefiando lares no mundo colonial, mas relativiza essa informação, considerando sua maior incidência nas áreas urbanas, já que "a mulher sozinha, com filhos consumidores, dificilmente conseguiria sobreviver enquanto ‘cabeça de família' em área rural, sem escravos ou agregados.” (FARIA, 1998, 53).

Essas entregas de farinha foram subdivididas em três grupos: um primeiro e grande grupo com capacidade de fornecimento de 01 até 04 alqueires (de 30,22 a $120 \mathrm{~kg}$ ) por lavrador, formado por 142 entregas; um segundo grupo, de 6 a 10 alqueires (181,3 a 302,2 $\mathrm{kg}$ ), com 28 entregas e um terceiro grupo, de 12 a 32 alqueires (362,7 a 967,2 kg), formado por 18 entregas. Configura-se assim, a existência de uma hierarquia entre estes lavradores de farinha, sendo maior fornecedor o padre Francisco da Silva Ferreira, vendedor da única entrega de 32 alqueires $(967 \mathrm{~kg}$ ), ao preço de $\$ 480$ réis por alqueire, perfazendo $15 \$ 960$ (quinze mil novecentos e sessenta réis). O menor fornecedor foi Francisco Lopes, com apenas meio alqueire $(16,1 \mathrm{~kg})$, a $\$ 400$ réis o alqueire inteiro, em 13 de fevereiro. Infelizmente os dados disponíveis não permitem elucidar que regras ou negociações regularam o preço da

\footnotetext{
9 Correspondência e documentos relativos as novas Minas de Macacu, do Rio de Janeiro, de que era superintendente Manuel Pinto da Cunha e Souza - 1786 a 1790. Seção de Manuscritos. Biblioteca Nacional. Catálogo 09,3,017-021

${ }^{10}$ Foi desconsiderada, nas três listagens, a repetição de nomes, sendo analisadas em conjunto e abordadas as três datas de compra como listagens independentes entre si, na busca de caracterizar essa oferta do produto.
} 
farinha nesses três meses de fornecimento. Talvez a explicação possa ser a distância entre o local de produção e o de entrega da farinha, no "paiol da Cachoeira", o que traria diferença no preço do frete ou mesmo, a qualidade do produto.

Uma oscilação de preços ligada à quantidade de produtores/mês pode ser observada no valor do alqueire da farinha indicado pela Tabela 2. Para os produtores que venderam maiores quantidades, o preço do alqueire foi valorizando durante esse trimestre de fornecimento: em janeiro, 500 réis; fevereiro, 520 e em maio chegava-se a 640 réis por alqueire. No caso dos menores fornecedores, em janeiro o alqueire estava 'cotado' a 360 réis, diminuindo esse valor para 320 em fevereiro, mês em que maior número de fornecedores entregou remessas do produto e em maio, subiu para 400 réis. Outro aspecto que pode ser considerado a respeito dos preços do alqueire de farinha se refere ao fato de que o Estado fixava o valor do alqueire a ser pago aos produtores, e que nem sempre era do agrado dos mesmos, conforme carta da Câmara da vila de Macacu encaminhada ao rei D. João V, em 1724:

Aos Reais Pés de V. Majestade fazemos presente em como os moradores desta Vila e seu distrito estão atualmente concorrendo com as farinhas necessárias para os socorros da infantaria e fortalezas e também para os aprestos das rotas com tanta prontidão de cessão experimenta falta alguma e requerendo este ofício pagamentos pelo estado da terra, o Provedor da Real Fazenda de Vossa Majestade o faz muito pelo contrário porque valendo as farinhas que se vendem ao Povo cinco e seis patacas o alqueire ele a manda pagar por três e a este respeito tudo o mais e como seja em grande prejuízo dos Vassalos de Vossa Majestade de que repetidas vezes se nos queixam, recorremos a Real Grandeza de Vossa Majestade que se digne ordenar o que for Servido atendendo o bem comum destes Moradores a Real Pessoa de Vossa Majestade desde muitos anos como seus Vassalos havemos mister. Vila de Santo Antônio de Sá, em Câmara, 20 de Outubro de 1724 e eu Domingos Gonçalves Calheiros (?) escrivão da Câmara o sobrescrevi. ${ }^{11}$

$\mathrm{Na}$ verdade, a análise somente desse momento em que se registrou a compra da farinha, dentre outros que não seria possível aqui demonstrar, não contribui de forma significativa para a compreensão da real capacidade de produção farinheira de Macacu. Serviu sim para demonstrar que havia em Macacu uma produção farinheira excedente, de caráter mercantil e comercializável. Infere-se que a região atendia às necessidades de autoconsumo, abastecimento e também de atendimento das demandas alimentares da administração colonial. Contudo, essa listagem de 196 produtores de farinha não representa, nem de longe, o número de produtores listados em outra fonte.

\footnotetext{
${ }^{11}$ 1724, Outubro, 10, vila de Santo Antônio de Sá. Carta dos oficiais da Câmara da vila de Santo Antônio de Sá ao rei D. João $\mathrm{V}$, sobre o fornecimento de farinha que se faz às fortalezas e o socorro da infantaria, e queixandose do preço de venda da farinha e a solicitação feita para corrigir desníveis de custos. AHU-Rio de Janeiro, cx. 15, doc. 83. AHU_ACL_CU_017, CX.14, D. 1582.
} 
$\mathrm{Na}$ "Discripção do que contém o distrito da Vila de Santo Antônio de Sá de Macacu feita por ordem do vice-rei do estado do Brasil, conde de Resende" ${ }^{\prime 12}$, de 1797, se concentram, isoladamente, também volumosos dados socioeconômicos para a região de Macacu no século XVIII. Essa fonte é um documento ímpar: constitui-se no conjunto mais completo de informações, tomadas isoladamente, acerca da situação socioeconômica da região do Macacu para o final do setecentos, reunindo milhares de dados criteriosamente recolhidos e compilados. Proprietários de terras e escravos, serrarias, oficinas e tavernas são apresentados numa longa lista nominativa. Para cada proprietário ou proprietária listados, dados como a extensão de sua propriedade, estado civil, número de filhos por sexo, faixa etária e o levantamento de cada escravaria por sexo e grupo etário (se criança ou adulto). As produções de açúcar, farinha de mandioca, aguardente, arroz, milho e feijão aparecem detalhadas, assim como a quantidade de bois, cavalos, ovelhas, bestas (mulas ou burros) e poldros de cada um dos listados. Outros dados complementam a fonte: produção de telhas, tijolos e a atividade madeireira na região. Para as madeiras, além de uma listagem das espécies vegetais as quais se tinha interesse, ou seja, para aplicação em obras civis e hidráulicas, a atividade extrativa vem apresentada pela quantidade de cada subproduto obtido desta extração, como tábuas e 'pernas de serra', entre outros. Todos esses dados vem acompanhados de longo relatório, onde o anônimo autor apresenta os limites geográficos da Vila de Santo Antônio de Sá (Macacu), capacidade produtiva da terra, discussão de problemas observados, o sistema hídrico da região do Macacu, estradas etc. No "Resumo Geral dos Engenhos, Fogos, Almas, Rendimento etc da Vila de Santo Antonio de Sá de Macacu” existente ao final da Discripção, pode-se observar que a região de Macacu possuía, em 1797, 11.538 habitantes, sendo 6.831 cativos (59,2\%), em contraste com 4.707 livres (40,7 \%), e uma intensa atividade econômica com 27 engenhos de açúcar, 02 fábricas de beneficiamento de arroz, 238 engenhos de farinha e 10 olarias. Um total de 649 lavradores produzia farinha de mandioca ao lado do trabalho de 30 oficiais de ofício, 55 serradores e 66 proprietários de tavernas.

Se tem considerado já superada na historiografia brasileira, a visão da sociedade colonial segmentada em dois únicos grupos antagônicos: senhores de engenho e escravos. Silva criticou essa abordagem situando que, até em regiões onde, por pressuposto, deveríamos encontrar a mais nítida polarização senhor/escravo, uma análise mais detalhada nos permite ver estratos sociais mais variados. (SILVA, 1990, 65). Desta forma, esse esquemático

\footnotetext{
${ }^{12}$ Discripção do que contém o distrito da Vila de Santo Antônio de Sá de Macacu feita por ordem do vice-rei do estado do Brasil, conde de Resende [D. José Luís de Castro]. 07 de abril de 1797. Arquivo Histórico Ultramarino-Rio de Janeiro. Cx. 165, doc. 62 e AHU_ACL_CU_017, Cx.161, D. 12071. Contém anexo com mapas (planilhas).
} 
binômio se vê 'desqualificado', já que entre estes dois 'extremos' constatou-se existir uma miríade de pequenos produtores escravistas não excluídos na estrutura da sociedade colonial, mas integrados a elas através de uma peculiar atividade econômica: a produção de alimentos por homens livres ou libertos.

Há que se relativizar o termo subsistência, utilizado para definir a produção externa ao binômio senhor de engenho/escravos por Caio Prado Júnior, ao explanar sobre o que intitulou de caráter geral da colonização brasileira, no sentido que a economia colonial se voltaria essencialmente para a exportação, por ser "uma colônia destinada a fornecer ao comércio europeu alguns gêneros tropicais de grande expressão econômica. É para isto que se constituiu." (PRADO JUNIOR, 1994, 41). Neste sentido "tudo mais que nela existe, e que, aliás, será sempre de pequena monta, é subsidiário e destinado unicamente a amparar e tornar possível a realização daquele objetivo essencial. Inclui-se aí a economia de subsistência." (PRADO JUNIOR, 1994, 41). A expressão economia de subsistência é hoje imprecisa para caracterizar estruturalmente o sistema produtivo colonial. Este era anteriormente visto a partir da ideia de absoluta autossuficiência, mantida pela autonomia das unidades de produção para exportação. Segundo Antônio Carlos Jucá de Sampaio,

os trabalhos existentes já comprovaram de forma definitiva o caráter comercial da produção de alimentos. A posse de escravos por parte destes produtores (muitos com dezenas deles), e a sua relação com o mercado (patente na análise das dívidas ativas/passivas e na especialização da produção), acabam com a falsa relação estabelecida por diversos historiadores entre "produção de alimentos" e "produção de subsistência", entendida aqui como produção voltada para o autoconsumo. (SAMPAIO, 1994, 20)

José Newton Coelho Meneses, em trabalho voltado para Minas Gerais, discutiu a respeito desse aspecto:

(...) é temerária a classificação, às vezes feita aprioristicamente, do tipo de economia agrícola praticada nas minas gerais setecentistas. "Agricultura de subsistência", adjetivação usada por muitos autores, se enquadraria como caracterização ideal? Maria Yedda Linhares já propõe esse questionamento em texto aqui citado $^{13} \mathrm{e}$, no entanto, tantos anos passados, tal caracterização simplista ainda persiste. (MENESES, 2000, 98).

Portanto, para que se possa dizer que a produção agrícola "macacuana", com seu caráter pequeno escravista, fosse de 'subsistência', deveria esta abranger as características citadas por Meneses. Entretanto, dado o estabelecimento dessa produção na conjuntura de uma agricultura de abastecimento, o termo não parece, de fato, ser o mais preciso para a

\footnotetext{
${ }^{13}$ Sob o mencionado ver: LINHARES, 1983.
} 
caracterização. As próprias fontes para o século XVIII parecem caminhar em direção contrária à ideia de subsistência, já que, "os senhores de engenho pela maior parte abandonam totalmente a cultura da mandioca, achando melhor conveniência em comprá-la do que em plantar a farinha para a sustentação da sua família e dos seus escravos..."14.

Segundo Silva, os pequenos cultivadores e roceiros não se encontravam esquematicamente subordinados aos plantadores de cana. Com poucos escravos, produziam gêneros para o mercado, num estrato social de produtores pequeno escravistas. Esta mesma conjuntura traria a possibilidade de duas situações distintas: "nem o abastecimento da plantagem, ou sua escravaria, se dava em termos de uma unidade retroprodutora (...) e nem tampouco era a plantagem, através do seu setor natural, responsável pelo abastecimento dos núcleos urbanos, das tropas ou da matalotagem das naus." (SILVA, 1990, 68). Infere-se que a produção da farinha de mandioca e de outros gêneros agrícolas era atividade generalizada em Macacu, com vários lavradores integrando, ao lado dos maiores detentores de terras e homens, um grande conjunto de produtores. Produção não no sentido de subsistência, mas de autosustento, sendo esta orientada também para o mercado visando garantir, através da venda ou troca, o acesso a outros bens. Configura-se assim, no contexto da economia do recôncavo da Guanabara, um nicho econômico 'macacuano' formado por uma produção de caráter mercantil e de estrutura pequeno escravista. Acredito ser esta a característica básica da economia do vale do Macacu. Sampaio, analisando a estrutura socioeconômica da Vila de Magé para a segunda metade do século XIX apresentou características de uma produção pequeno-escravista de alimentos, já que temos mais uma vez a demonstração clara do caráter comercial da produção de alimentos no período, ainda quando os agricultores a ela ligados tivessem poucos ou nenhum escravo. (SAMPAIO, 1994, 20).

Após essas considerações, analisemos a fonte da "Discripção". A mesma traz dados recolhidos apenas para 1797. Entretanto, se vistos em conjunto com os dados referentes aos anos de 1778 (Relatório do Marquês do Lavradio), 1790 (Annaes do Rio de Janeiro, de Bhaltazar Lisboa) e 1794/95 (Visitas Pastoraes de monsenhor Pizarro), aqueles oferecem regularidade no tocante ao volume e espécies vegetais produzidas em Macacu. Infere-se daí que essa produção se deu, nestes anos de referência - até mesmo por sua proximidade - com base em semelhante estrutura socioeconômica. Percebeu-se na "Discripção" as seguintes categorias de propriedades:

\footnotetext{
${ }^{14}$ Carta do Conde de Resende à Coroa comunicando as razões que se tem oposto ao aumento da cultura da mandioca...Rio de Janeiro, 21 de abril de 1798. Arquivo Nacional, Códice 69, vol.8. Apud SILVA, 1990, 68
} 
CATEGORIA I- Senhores de engenho - 27 integrantes; agrega os produtores de açúcar, embora também produzissem farinha;

CATEGORIA II- Fábricas de farinha - 238 integrantes; abrange propriedades especializadas na produção sistemática de farinha de mandioca;

CATEGORIA III- Lavradores - 649 integrantes; categoria representada por indivíduos voltados mais para a produção de farinha, arroz, milho, feijão, sem caráter de especialização. Apesar da produção de farinha ser realizada pelos integrantes das três categorias, e uns poucos lavradores chegarem a produzir algum açúcar, a última categoria, de Lavradores, agrupa indivíduos excluídos das duas categorias anteriores.

A primeira categoria analisada a partir da Discripção..., é a dos senhores de engenho, vistos aqui em comparação com as demais categorias de produtores rurais, de acordo com a tabela abaixo:

\begin{tabular}{|l|c|c|c|}
\hline \multicolumn{1}{|c|}{ CATEGORIAS } & $\mathrm{N}^{\mathbf{c}}$ & Arrobas & Escravos \\
\hline Senhores de engenho & 27 & 18.869 & 1.499 \\
\hline Fábricas de farinha & 238 & 1.450 & 2.746 \\
\hline Lavradores & 649 & 2.778 & 2.167 \\
\hline \multicolumn{1}{|c|}{ TOTAIS } & 914 & 23.097 & 6.412 \\
\hline
\end{tabular}

TABELA 3: Posse de escravos por grupos de produtores e arrobas de açúcar produzido ${ }^{15}$

Dos 914 produtores que integram as três categorias listadas na Discripção, apenas 27 $(2,9 \%)$ dedicavam-se à produção de açúcar. Atuavam em contraste com 238 fabricantes de farinha $(26 \%)$ e 649 lavradores $(71 \%)$. Nas propriedades listadas, já que fabricantes de farinha e lavradores também produziram pequenas quantidades de açúcar, fabricaram, em 1797, um total de 23.097 arrobas do produto. Desta produção, 81,6 \% (18.869 arrobas) foi realizada pelos engenhos de açúcar, que concentravam, num universo de 6.412 escravos, a posse de 1.499 cativos $(23,3 \%)$, numa média de 55 cativos por unidade. As 238 unidades classificadas como fábricas de farinha, produziram 1.450 arrobas $(6,2 \%)$ de açúcar, tendo no total, 2.746 escravos (42,8\%), numa média de 11 escravos por produtor. Por sua vez, os 649 lavradores produziram 2.778 arrobas (12\%) e concentraram a posse de 2.167 escravos. Média de 03 cativos por produtor. Tomadas em conjunto, 'fábricas de farinha" e lavradores integram

\footnotetext{
${ }^{15}$ Discripção do que contém o distrito da Vila de Santo Antônio de Sá de Macacu feita por ordem do vice-rei do estado do Brasil, conde de Resende [D. José Luís de Castro]. 07 de abril de 1797. Arquivo Histórico Ultramarino-Rio de Janeiro. Cx. 165, doc. 62 e AHU_ACL_CU_017, Cx.161, D. 12071. Contém anexo com mapas (planilhas).
} 
887 propriedades. Também produziram açúcar, mas apenas 4.228 arrobas (18,3\%), numa média baixa de 4,7 arrobas $(70,5 \mathrm{~kg})$ por unidade/ano. Na posse de escravos, lavradores e fábricas de farinha possuíam um total de 4.913 cativos, média de 05 escravos por propriedade. Nesse quadro, infere-se que, dada a pequena média produtiva de açúcar, este grande grupo de produtores moía sua cana nos engenhos, pagando taxas de costume pelo seu uso.

Observemos agora a produção dos demais gêneros agrícolas: farinha de mandioca, feijão, arroz e milho, que define o perfil pequeno escravista para a região:

\begin{tabular}{|c|c|c|c|c|c|c|c|c|c|c|}
\hline CATEGORIA & $\mathrm{N}^{\circ}$ & Farinha & $\%$ & Feijão & $\%$ & Arroz & $\%$ & Milho & $\%$ & Escravos \\
\hline $\begin{array}{c}\text { Senhores de } \\
\text { engenho }\end{array}$ & 27 & 3.671 & 5,41 & 441 & 12,6 & 196 & 1,1 & 392 & 9,7 & 1.499 \\
\hline $\begin{array}{c}\text { Fábricas de } \\
\text { farinha }\end{array}$ & 238 & 38.633 & 56,94 & 1.489 & 42,7 & 11.397 & 66,4 & 1.811 & 44,9 & 2.746 \\
\hline Lavradores & 649 & 25.548 & 37,65 & 1.557 & 44,7 & 5.573 & 32,5 & 1.833 & 45,4 & 2.167 \\
\hline TOTAIS & 914 & 67.852 & 100,0 & 3.487 & 100,0 & 17.166 & 100,0 & 4.036 & 100,0 & 6.412 \\
\hline
\end{tabular}

TABELA 4: Posse de escravos e alqueires de farinha, feijão e milho produzidos em $1797^{16}$

Os 27 senhores de engenho são, em volume de produção, os menores produtores de gêneros alimentícios. Dos 67.852 alqueires de farinha produzidos, foram responsáveis por 3.671 alqueires $(5,41 \%)$, o mesmo se dando para o feijão $(12,6 \%)$, arroz $(1,1 \%)$ e milho (9,7\%). Esses engenhos também produziram, em conjunto, um total de 582 pipas de aguardente e apenas 01 alqueire de goma (polvilho). Sustenta-se nesse trabalho que os engenhos de açúcar não produziram gêneros alimentícios a ponto de garantir seu próprio abastecimento. Quando postos em contraste com as unidades de produção das outras duas categorias, torna-se claro que não foram nos engenhos que se produziram alimentos responsáveis pelo seu próprio autossustento, nem para abastecimento da região e, muito menos fornecer, em quantidades consideráveis, farinha, arroz, milho e feijão para a cidade do Rio de Janeiro. As 238 fábricas de farinha, por sua vez, constituíam o "carro-chefe" da atividade farinheira, o que ratifica o caráter especializado de Macacu na produção desse gênero. Produziram 56,93\% de toda a farinha (38.628 alqueires) fabricada na região. Também foram responsáveis pela produção, em conjunto, de goma, com 92 alqueires. A Discripção

\footnotetext{
${ }^{16}$ Discripção do que contém o distrito da Vila de Santo Antônio de Sá de Macacu feita por ordem do vice-rei do estado do Brasil, conde de Resende [D. José Luís de Castro]. 07 de abril de 1797. Arquivo Histórico Ultramarino-Rio de Janeiro. Cx. 165, doc. 62 e AHU_ACL_CU_017, Cx.161, D. 12071. Contém anexo com mapas (planilhas).
} 
registra que essas unidades produtivas não fabricaram uma única pipa de aguardente sequer. Os fabricantes de farinha produziram $44,8 \%$ de todo o milho (1.811 arrobas) e $42,7 \%$ do feijão (1.489 arrobas). Chega-se, por fim, à categoria dos Lavradores: estes têm em sua conta, $37,65 \%$ da farinha (25.548 alqueires) e 44,6\% do feijão (1.557 arrobas). Também produziram 5.573 arrobas de arroz $(32,4 \%)$ e 1.833 arrobas de milho $(45,4 \%)$.

No computo dos proprietários de 1 até 5 escravos e calculando-se os percentuais sobre o total de 649 Lavradores, é possível matizar com cores mais vivas as propriedades pequeno escravistas:

\begin{tabular}{|c|c|c|c|c|l|c|}
\hline Escravos por produtor & 01 & 02 & 03 & 04 & 05 & TOTAL \\
\hline $\mathrm{N}^{\mathbf{o}}$ de Produtores & 90 & 80 & 66 & 44 & 36 & 316 \\
\hline$\%$ & 13,86 & 12,32 & 10,17 & 6,80 & 5,54 & 48,69 \\
\hline
\end{tabular}

TABELA 5: Posse de 1 a 5 escravos por Lavrador $-1797^{17}$

Destes, $90(13,86 \%)$ possuíam apenas 01 escravo, seguidos de $80(12,32 \%)$ que detinham 02 escravos cada. Possuir apenas 03 escravos era a condição de 66 lavradores $(10,17 \%)$. Respectivamente, 04 e 05 escravos serão possuídos por cada um dos $44(6,80 \%)$ e 36 (5,54\%) Lavradores listados, perfazendo-se um percentual de $48,69 \%$ sobre o total. O grupo dos que não possuíam nenhum escravo, na categoria dos Lavradores perfazia um total de 206 homens num percentual expressivo de 31,74\%, quando calculado sobre o número total de Lavradores (649). Em relação ao total de homens e mulheres presentes em toda a Discripção, ou seja, 914, esse percentual chega a 22,53\%. É possível, portanto, visualizar-se o grupo dos pequenos produtores escravistas do distrito da Vila de Santo Antônio de Sá de Macacu. Dos 27 senhores de engenho, 24 deterão, individualmente, a posse de 14 até 95 escravos. Os donos de engenho menos "afortunados" serão apenas dois: Jerônimo Gomes Pacheco, com 08 escravos e Francisco Xavier da Costa, com 09. Totalmente atípico nesse grupo revela-se Antônio de Oliveira Braga: sozinho ostentava a posse de 207 cativos, ou seja, $13,8 \%$ do total de 1.499 escravos pertencentes a essa categoria. Na categoria dos donos de fabricas de farinha, 66 produtores constituirão a faixa dos detentores de 1 a 5 escravos. Treze não dispunham de cativos e somente uma terá 90 cativos: uma fazenda da Ordem do Carmo,

\footnotetext{
${ }^{17}$ Discripção do que contém o distrito da Vila de Santo Antônio de Sá de Macacu feita por ordem do vice-rei do estado do Brasil, conde de Resende [D. José Luís de Castro]. 07 de abril de 1797. Arquivo Histórico Ultramarino-Rio de Janeiro. Cx. 165, doc. 62 e AHU_ACL_CU_017, Cx.161, D. 12071. Contém anexo com mapas (planilhas).
} 
que é citada duas vezes na fonte: como proprietária de engenho e como dona de fábrica de farinha, em propriedades com áreas territoriais diferentes. Por sua vez, Balthazar da Silva Lisboa informa que em 1790 a Vila, ou seja, o conjunto de suas freguesias era habitado por cerca de 30 mil pessoas. Os moradores produziam açúcar e as safras beiravam em torno de 900 a 1.000 caixas, com 2.273 escravos. (LISBOA, 1967)

Portanto, a Vila de Santo Antônio de Sá de Macacu, com suas freguesias, ao longo do século XVIII caracterizava-se por apresentar, em conjunto com poucas plantations, uma economia de mercado interno de gêneros variados, que englobava o cultivo de arroz, feijão, farinha, milho e fumo; a extração e comércio de madeiras, criação de aves, com comercialização de ovos, além da criação de porcos. Toda esta produção tinha parte consumida na própria Macacu e parte exportada para as localidades vizinhas, inclusive a cidade do Rio de Janeiro, através dos rios da região. Estes rios em muito auxiliaram o comércio, posto que muitos, ou se constituíram como afluentes do maior rio do recôncavo da Guanabara, o Macacu, ou tinham sua foz diretamente na Baía. A maior parte da população de Macacu era formada por pequenos e médios proprietários, muitos com pequenas escravarias ou até mesmo sem registrar a posse de sequer um cativo. (AMANTINO, CARDOSO, 2008, 104-105)

Essa continuada produção serviu também, como já se frisou, para abastecer as populações que participaram da conquista dos Sertões do Macacu. As fontes disponíveis na "Correspondência e documentos relativos às novas Minas de Macacu," (1786-1790) apresentam outro exemplo dessa dinâmica de abastecimento, através de duas relações de aquisição de gêneros alimentícios, no caso farinha e feijão, também junto a vários produtores situados nas regiões do entorno dos Sertões do Macacu.

A primeira, uma relação de compra de farinha de mandioca encaminhada pelo capitão mor da vila de Macacu (Santo Antônio de Sá), Joaquim José da Fonseca, ao coronel Manoel Soares Coimbra, comandante geral dos Sertões do Macacu em 20 de dezembro de 1786. Essa farinha tinha o objetivo de sustentar as tropas que fariam a ocupação e controle dos Sertões.

\begin{tabular}{|l|c|c|c|}
\hline Bairros, Pessoas que as remeteram e Lavradores a quem pertencem & Alqueires & Preços & Liquido \\
\hline $\begin{array}{l}\text { Magé } \\
\begin{array}{l}\text { O Sargento das Ordenanças do dito Bairro Ignacio José Alvares } \\
\text { remeteu pertencente a vários lavradores }\end{array}\end{array}$ & 25 & 640 & $16 \$ 000$ \\
\hline Porto das Caixas & 222 & 400 & $88 \$ 800$ \\
\hline
\end{tabular}

18 Correspondência e documentos relativos as novas Minas de Macacu, do Rio de Janeiro, de que era superintendente Manuel Pinto da Cunha e Souza - 1786 a 1790. Seção de Manuscritos. Biblioteca Nacional. Catálogo 09,3,017-021. 
O Cabo Jeronimo Dias Lopes remeteu dos Armazéns de Bento de Amorim, Antônio de Magalhães, Manoel Alvares Pinto, Francisco José Ribeiro, José Machado de Aguiar e de Antônio José de Betancourt pertencente a vários Lavradores

Porto de Vila Nova

O Alferes Domingos João fez remeter pertencente a vários Lavradores

Magé

O Alferes Francisco Joaquim de Araújo e o Sargento João Caetano recolheram dos Armazéns de Martinho José, Francisco Nunes, Manoel Fernandes Lessa, José de Jesus, Manoel do Rego pertencentes a vários Lavradores.

E do Porto da Vila Nova apreenderam pertencentes a vários Lavradores

E do Porto das Caixas apreenderam nos Armazéns de Pedro Alves pertencentes a vários Lavradores

Bairros, Pessoas que as remeteram e Lavradores a quem pertencem

Transporte da Lauda em frente

Porto das Caixas

O Soldado João Pereira da Silva dos Armazéns de Antônio de Magalhães, José Delfim, José de Brito, José de Brito, Antônio José

Betancourt e do Capitão André Alves Pereira Viana pertencentes a vários Armazéns

\section{Magé}

O Sargento João Caetano recolheu por Lista pertencentes a vários Lavradores

Apreendida nesta Vila

A Manoel de Araújo Viana

A José Caetano Monteiro

A Antônio José Salgado

A João Barbosa

A Boaventura do Rego

A Antônio Manoel

Termo desta Vila

O Alferes Manoel Mendes de Magalhães recolheu pertencentes a vários Lavradores

\section{Macacu}

O mesmo Alferes Manoel Mendes de Magalhães recolheu pertencentes a vários Lavradores

Apreendida nesta Vila

A Anacleto Marcelino.

A Antônio José de Souza Salgado.

Porto das Caixas

O Sargento João Caetano fez recolher pertencentes aos Armazéns de José Delfim e de Antônio de Magalhães.

\begin{tabular}{|c|c|c|c|}
\hline & 1713 & & $791 \$ 170$ \\
\hline $\begin{array}{c}\text { Bairros, Pessoas que as remeteram e Lavradores a quem } \\
\text { pertencem }\end{array}$ & Alqueires & Preços & Liquido \\
\hline Transporte da Lauda em frente & 1713 & & $791 \$ 170$ \\
\hline $\begin{array}{l}\text { Porto de Vila Nova } \\
\text { O Alferes Domingos Leão fez recolher pertencente a Quitéria } \\
\text { Teresa }\end{array}$ & $\begin{array}{l}46 \\
04\end{array}$ & $\begin{array}{l}560 \\
560\end{array}$ & $\begin{array}{c}25 \$ 760 \\
2 \$ 240\end{array}$ \\
\hline
\end{tabular}




\begin{tabular}{|c|c|c|c|}
\hline E a Aleixo Rodrigues & & & \\
\hline $\begin{array}{l}\text { Caxoeira de Macacu } \\
\text { Por Relação do Sargento da Guarda do Paiol de Ventura Paes } \\
\text { recolheram vários Lavradores em farinha }\end{array}$ & 337 & 400 & $134 \$ 800$ \\
\hline Soma & 2100 & & $953 \$ 970$ \\
\hline $\begin{array}{l}\text { Somam os alqueires de farinha declarados nesta Relação dois mil } \\
\text { preços importam novecentos cinquenta e três mil novecentos e sete } \\
\text { Antonio de Sá. } 20 \text { de Dezembro de } 1786 \text {. Joaquim José da Fonseca }\end{array}$ & & & $\begin{array}{l}\text { elos seus } \\
\text { de Santo }\end{array}$ \\
\hline $\begin{array}{l}\text { TABELA 6- Relação das farinhas que adquiri por este Distrito depois da te } \\
\text { que em outra Relação expus na Presença de V. Excia que importam } 116 \\
\text { Maio pretérito precedente que de sua remessa, Donos, preços e liquido }\end{array}$ & & & $\begin{array}{l}\text { es e meio } \\
\text { de } 22 \text { de } \\
\text { eguem } \\
19\end{array}$ \\
\hline
\end{tabular}

A segunda tabela traz informações similares, mas agora para remessas de feijão, aquisição também feita pelo capitão-mor e encaminhada ao coronel Soares Coimbra, na mesma data, 20 de dezembro de 1786. Ambas as relações apresentam nomes dos lavradores, seus locais de moradia e roças tais como Magé, Tapacorá, Porto das Caixas, vila de Macacu, "Caxoeira" de Macacu (ao norte na fronteira com os Sertões), subúrbios da Vila (de Macacu), termo da Vila, farinha e feijão apreendidos na Vila etc. Todas são regiões as quais, se não no interior, no entorno do vale do rio Macacu. Uma região, portanto, grande produtora de gêneros para abastecimento.

\begin{tabular}{|c|c|c|c|}
\hline Bairros, Pessoas que as remeteram e Lavradores a quem pertencem & Alqueires & Preços & Liquido \\
\hline $\begin{array}{l}\text { Subúrbios desta Vila } \\
\text { Bento de Souza Couto } \\
\text { Antônio de Magalhães } \\
\text { Joaquim José da Fonseca } \\
\text { Antônio Marques } \\
\text { Manoel dos Santos Valadares }\end{array}$ & $\begin{array}{c}02 \\
18 \\
3 \\
11 \frac{1}{1 / 2} \\
11 \frac{1 / 4}{}\end{array}$ & $\begin{array}{l}640 \\
640 \\
640 \\
640 \\
640\end{array}$ & $\begin{array}{c}1 \$ 280 \\
11 \$ 520 \\
1 \$ 920 \\
7 \$ 360 \\
7 \$ 200\end{array}$ \\
\hline $\begin{array}{l}\text { Soledade } \\
\text { O Sargento Joaquim José da Silva fez recolher de vários } \\
\text { Lavradores }\end{array}$ & 24 & 500 & $12 \$ 000$ \\
\hline $\begin{array}{l}\text { Vindos a esta Vila } \\
\text { De José da Costa }\end{array}$ & 12 & 500 & $6 \$ 000$ \\
\hline Transporte da Lauda em frente & $\frac{\text { Alqueires }}{813 / 4}$ & Preços & $\begin{array}{c}\text { Liquido } \\
47 \$ 280\end{array}$ \\
\hline De Francisco das Chagas & 4 & 500 & $2 \$ 000$ \\
\hline $\begin{array}{l}\text { Maracanã } \\
\text { O Sargento José Joaquim Henrique fiz recolher de vários } \\
\text { Lavradores }\end{array}$ & 80 & 500 & $40 \$ 000$ \\
\hline Tapacorá & $408^{1 / 2} \mathrm{e}$ & 500 & $204 \$ 437$ \\
\hline
\end{tabular}

${ }^{19}$ Carta do Capitão Mor Joaquim José da Fonseca ao Tenente Coronel Manoel Soares Coimbra Vila de Macacu. 20 de dezembro de 1786. Correspondência e documentos relativos às novas minas de Macacu, do Rio de Janeiro, de que era superintendente geral Manuel Pinto da Cunha e Souza. Rio de Janeiro: [s.n.], 1786 - 1790.5 vol. (1338 p.), Cópia. Localização: Manuscritos - 09,03,017-021. (01, 101, 110). 


\begin{tabular}{|c|c|c|c|}
\hline $\begin{array}{l}\text { Do Ajudante Supra Manoel José beça Negrão fiz recolher de vários } \\
\text { Lavradores }\end{array}$ & $1 / 24^{a}$ & & \\
\hline $\begin{array}{l}\text { Porto das Caixas } \\
\text { O mesmo Ajudante fiz recolher de vários Lavradores }\end{array}$ & 22 & 500 & $11 \$ 000$ \\
\hline $\begin{array}{l}\text { Tapacorá } \\
\text { O Capitão Alexandre Alvares de Azevedo fez recolher de vários } \\
\text { Lavradores }\end{array}$ & 34 & 500 & $17 \$ 000$ \\
\hline $\begin{array}{l}\text { Porto das Caixas } \\
\text { O Cabo Jerônimo Dias fez recolher de Ignácio Francisco }\end{array}$ & 03 & 500 & $1 \$ 500$ \\
\hline $\begin{array}{l}\text { Subúrbios desta Vila } \\
\text { De Luiz Vieira } \\
\text { De Ignácio Luiz de Souza } \\
\text { De Joana Maria } \\
\text { De Francisco da Costa Bernardo } \\
\text { De Vicente Cardoso } \\
\text { De Manoel de Araújo Viana }\end{array}$ & $\begin{array}{l}12 \\
02 \\
02 \\
06 \\
06 \\
10\end{array}$ & $\begin{array}{l}500 \\
500 \\
500 \\
500 \\
500 \\
500 \\
\end{array}$ & $\begin{array}{c}6 \$ 000 \\
10 \$ 000 \\
10 \$ 000 \\
3 \$ 000 \\
3 \$ 000 \\
3 \$ 000\end{array}$ \\
\hline $\begin{array}{l}\text { Cachoeira de Macacu } \\
\text { Por Lista que me deu o Sargento da Guarda da Cachoeira Francisco } \\
\text { José da Silva recolheram vários moradores ao Paiol da dita Guarda }\end{array}$ & 133 & 500 & $66 \$ 500$ \\
\hline Soma & $\begin{array}{c}84 \frac{1 / 2}{2} e^{1 / 2} \\
4^{a}\end{array}$ & & $408 \$ 717$ \\
\hline \multicolumn{4}{|c|}{$\begin{array}{l}\text { Somam os alqueires de feijão relatado oitocentos e quatro alqueires e meia e meia quarta que pelos } \\
\text { seus preços importam quatrocentos e oito mil setecentos e dezessete reis salvo erro. Vila de Santo } \\
\text { Antônio de Sá. } 20 \text { de Dezembro de } 1786 \text {. Joaquim José da Fonseca }\end{array}$} \\
\hline $\begin{array}{l}\text { TABELA } 7 \text { - Relação do feijão que adquiri por este Distrito para forn } \\
\text { destacado no Sertáo de Macacu até as Novas Minas do Canta Galo de } \\
\text { Manoel Soares Coimbra }{ }^{20} \text { Fonte: Novas Minas de Macacu. Original Man }\end{array}$ & 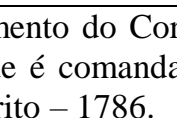 & & se acha \\
\hline
\end{tabular}

As tabelas também trazem as quantidades, preços por alqueire e valores pagos a cada produtor pelo conjunto de suas vendas. É certo porém comentar que se buscou, durante a ocupação dos Sertões do Macacu, estabelecer roças em seu interior para a produção de gêneros básicos como mandioca, feijão e milho, este último em especial para alimentar as mulas e burros das tropas que transportavam esses gêneros.

As fontes presentes na Correspondência e documentos relativos às novas Minas de Macacu, ${ }^{21}$ demonstram também a presença de soldados, quer fossem de tropas pagas ou auxiliares, destinados a cuidar de roças de mandioca no interior dos Sertões, o que indica a busca de uma expansão da produção agrícola em direção ao hinterland das conquistas.

Por se tratar de uma região ocupada por florestas, inicialmente de muito difícil acesso, há uma busca incessante das autoridades em estabelecer produções agrícolas, em especial da mandioca para a produção de farinha. Em carta datada de 07 de outubro de 1786, enviada ao

\footnotetext{
${ }^{20}$ Carta do Capitão Mor Joaquim José da Fonseca ao Tenente Coronel Manoel Soares Coimbra Vila de Macacu. 20 de dezembro de 1786. Correspondência e documentos relativos às novas minas de Macacu, do Rio de Janeiro, de que era superintendente geral Manuel Pinto da Cunha e Souza. Rio de Janeiro: [s.n.], 1786 - 1790. 5 vol. (1338 p.), Cópia. Localização: Manuscritos - 09,03,017-021. (01, 103, 111).

${ }^{21}$ Correspondência e documentos relativos as novas Minas de Macacu, do Rio de Janeiro, de que era superintendente Manuel Pinto da Cunha e Souza - 1786 a 1790. Seção de Manuscritos. Biblioteca Nacional. Catálogo 09,3,017-021.
} 
vice-rei Luís de Vasconcelos e Sousa, o tenente-coronel Manoel Soares Coimbra, então oficial comandante das operações no interior dos Sertões do Macacu, relatou ter encontrado nos Sertões terras em capoeira e que tinha plantado feijão, mandioca e milho. Relatou também que mandou fazer uma derrubada de mato com 200 braças de comprimento por 100 de largura para roça, mas não concluiu a coivara por causa da chuva e "falta de Sol." Também comentou ao vice-rei ter achado uma roça que foi dos contrabandistas de ouro desses Sertões (ou ao menos na busca dele), com 96 braças de comprimento e 60 de largura com muito milho, "em um Rancho que pela tropa de Minas [Gerais] foi tudo reduzido a cinzas e por aproveitar aquela terra fiz plantação de feijão e milho deixando este lugar suficiente para meter mandioca como vou fazendo da que me vem vindo da Cachoeira tendo também já plantado do mesmo gênero todo o roçado que achei no sitio dos Lopes ${ }^{22}$ de que dei parte a V. Excia."23

$\mathrm{O}$ relato demonstra que formas de abastecimento e aproveitamento dos espaços possíveis para a produção de gêneros alimentícios - inclusive os deixados por contrabandistas - foram buscados. Dados como esses atravessam as fontes, mas a ocupação desses espaços era insuficiente e é possível perceber a urgência em se buscar suprir essas necessidades.

Numa outra carta, de 15 de março de 1787, enviada também ao vice-rei, Soares Coimbra ainda se mostrava ocupado em buscar meios de abastecimento, comunicando que em 28 de fevereiro havia chegado a Cantagalo uma tropa de bestas com peixe e bacalhau tendo havido distribuição pelas guardas, que estava empenhado na plantação de muito milho e feijão e pretendia ir plantando mandioca, "tendo bastantes ramas do que se plantou". Também notificou que havia colhido mais 11 alqueires de feijão, "tendo toda a colheita 36 alqueires." $\mathrm{Na}$ busca por providenciar alimentos, explicou que havia "um certo numero de Bestas ocupadas somente em conduzir farinha e feijão da Vila para a Cachoeira para socorrimento dos Destacamentos..." ${ }^{24}$ Contudo, nem sempre essas experiências davam certo, já que numa correspondência do mesmo Coimbra ao vice rei em 09 de fevereiro do mesmo ano, este noticiou que estava fazendo o aproveitamento de parte da colheita de feijão, colhendo milho e a mandioca colhida no sertão fora considerada excelente para tirar para plantação no mês de

\footnotetext{
${ }^{22}$ Os Lopes citados se tratam de Domingos e Dionízio Lopes, considerados contrabandistas de ouro e foragidos dos sertões.

${ }^{23}$ Carta do Tenente Coronel Manoel Soares Coimbra ao Vice Rei Luís de Vasconcelos Sousa. Minas Novas do Cantagalo. 07 de outubro de 1786. Correspondência e documentos relativos às novas minas de Macacu, do Rio de Janeiro, de que era superintendente geral Manuel Pinto da Cunha e Souza. Rio de Janeiro: [s.n.], 1786 - 1790. 5 vol. (1338 p.), Cópia. Localização: Manuscritos - 09,03,017-021. (01, 065, 073).

${ }^{24}$ Carta do Tenente Coronel Manoel Soares Coimbra ao Vice Rei Luís de Vasconcelos Sousa. Canta Galo. 15 de março de 1787. Correspondência e documentos relativos às novas minas de Macacu, do Rio de Janeiro, de que era superintendente geral Manuel Pinto da Cunha e Souza. Rio de Janeiro: [s.n.], 1786 - 1790.5 vol. (1338 p.), Cópia. Localização: Manuscritos - 09,03,017-021. (02, 328, 086).
} 
abril, "pois da rama que mandei vir da Cachoeira, não obstante as grandes recomendações e cautelas, chegava aqui a maior parte arruinada, de forma que não pegarão muitos pés". ${ }^{25}$

Portanto, a melhor solução para o abastecimento dos agentes sociais envolvidos na conquista dos Sertões do Macacu, até a fixação dessas roças, seria mesmo adquirir gêneros alimentícios de fora, comprados dos produtores de Macacu, como já demonstrado, adquirido dos existentes em freguesias limítrofes ou mesmo no Rio de Janeiro. A região de Macacu, praticamente no seu todo, se constituiu como importante celeiro de cereais na capitania do Rio de Janeiro, integrando, através das suas principais vias de acesso, os rios Macacu, Guapiaçu e outros, as regiões de sertões, ao conjunto do império colonial português e seu, no dizer de Russel-Wood (2009, p. 51-52), "Império luso-afro-brasileiro nascido do mar."

\section{Referências bibliográficas:}

AMANTINO, Marcia Sueli, CARDOSO, Vinicius Maia. Múltiplas Alternativas: diversidade econômica da Vila de Santo Antonio de Sá de Macacu - Século XVIII. HEERA. Revista de História Econômica \& Economia Regional Aplicada - Vol. 3 Nª 5, Jul-Dez 2008.

CARDOSO, Vinicius Maia. Fazenda do Colégio: Família, Fortuna e Escravismo no Vale do Macacu - Séculos XVIII e XIX. 01. ed. Rio de Janeiro: Livre Expressão Editora, 2012. v. 01. $355 \mathrm{p}$.

FARIA, Sheila de Castro. A Colônia em Movimento: Fortuna e Família no Cotidiano Colonial. Rio de Janeiro: Nova Fronteira, 1998. p.53.

LISBOA, Balthazar da Silva. Anais do Rio de Janeiro. Rio de Janeiro: Ed. Leitura, 1967 [1834-5].

MENESES, José Newton Coelho. O Continente Rústico: abastecimento alimentar nas Minas setecentistas. Diamantina, MG: Maria Fumaça, 2000.

PRADO JUNIOR, Caio. História econômica do Brasil. $38^{a}$ ed. São Paulo: Brasiliense, 1994.

RUSSELL-WOOD, A. J. R. (2009). Sulcando os mares: um historiador do império português enfrenta a "Atlantic History". História (São Paulo), 28(1), 2009.

SAMPAIO, Antônio Carlos Jucá de. Magé na crise do escravismo: sistema agrário e evolução econômica na produção de alimentos (1850/1888). Dissertação de Mestrado. Niterói: UFF, 1994.

SILVA, Francisco Carlos Teixeira. A morfologia da escassez: crises de subsistência e política econômica no Brasil Colônia (Salvador e Rio de Janeiro, 1600-1790). Tese de doutoramento. Niterói, UFF, 1990.

THE BAY AND ENVIRONS OF RIO DE JANEIRO, 1908. Stanford's general map of the Federal District, showing railroads, major and minor, as well as those projected. Site Old and Historic Maps of Rio de Janeiro. Disponível em <http://www.brazilbrazil.com/riomaps.html $>$ Acesso em: 20 novembro de 2008.

\footnotetext{
${ }^{25}$ Carta do Tenente Coronel Manoel Soares Coimbra ao Vice Rei Luís de Vasconcelos Sousa. Canta Galo. 09 de fevereiro de 1787. Correspondência e documentos relativos às novas minas de Macacu, do Rio de Janeiro, de que era superintendente geral Manuel Pinto da Cunha e Souza. Rio de Janeiro: [s.n.], 1786 - 1790. 5 vol. (1338 p.), Cópia. Localização: Manuscritos - 09,03,017-021. (02, 318, 070).
} 